\title{
HUBUNGAN IKLIM KERJA DENGAN KELELAHAN PADA TENAGA KERJA BAGIAN PRODUKSI DI PT HARAPAN JAYA GLOBALINDO PURWOKERTO TAHUN 2016
}

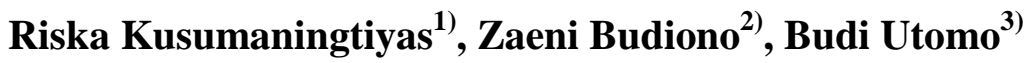 \\ Jurusan Kesehatan Lingkungan, Politeknik Kesehatan Kemenkes Semarang, \\ Jl.Raya Baturaden KM 12 Purwokerto, Indonesia
}

\begin{abstract}
Abstrak
Lingkungan kerja merupakan segala sesuatu yang berada di sekitar tenaga kerja yang dapat mempengaruhi tenaga kerja dalam melaksanakan tugas dan pekerjaan yang dibebankan.Iklim kerja yang panas dapat mempengaruhi kondisi tenaga kerja. Tujuan penelitian yaitu untuk mengetahui Hubungan Iklim Kerja dengan Kelelahan pada tenaga kerja bagian produksi. Metode penelitian adalah observasional dengan pendekatan Cross Sectional. Hasil Pengukuran iklim kerja pada bagian produksi menunjukan hasil rata-rata iklim kerja diatas NAB. Hasil pengukuran kelelahan kerja 20 orang $(66,66 \%)$ termasuk dalam kategori Normal, dan 10 orang (33,33\%) termasuk dalam kategori Kelelahan Kerja Ringan. Hasil analisis bivariate uji korelasi Simple Regression diketahui hubungan iklim kerja dengan kelelahan diketahui nilai $R=0,040, R^{2}=0,002, p=0,459$. Hasil analisis bivariate uji anova one way $p>0,05$. Penelitian disimpulkan bahwa hasil penelitian tidak ada hubungan antara iklim kerja dengan kelelahan. Tidak ada perbedaan kelelahan kerja di bagian bubut, otomotif, dan konstruksi. Disarankaan kepada perusahaan untuk pengendalian terhadap iklim kerja sebaiknya perlu ada penggantian atap dari asbes dengan atap genteng, untuk tenaga kerja sebaiknya saat istirahat tidak berada pada ruangan yang panas untuk meminimalisir waktu kontak dengan panas dan untuk peneliti selanjutnya disarankan dapat meneliti kadar debu dan limbah B3.
\end{abstract}

Kata kunci $\quad$ : Iklim Kerja, Kelelahan

\begin{abstract}
The Correlation Of Work Climate With Fatigue Towards Employees In Production Subdivision In PT Harapan Jaya Globalindo Purwokerto Year 2016. Work environment is everything around employees which can influence them in doing their duties and jobs given that in care of them. Hot work climate can influence employees condition. The purpose of this research is to find out the Correlation of Work Climate with Fatigue towards employees in production. The method used is Cross Sectional observational approach that is all of the employees. The result of work climate measurement in production show that the average result was above NAB. The result of work fatigue was 20 employees (66,66\%) included in Normal category, and 10 employees (33,33\%) included in Light Work Fatigue. The result of bivariate analysis one way anova test $p>0,05$. The result of work climate measurement in production subdivision consisted of lathe, automotive, and construction show that the average result was above $N A B$. The result of work fatigue was 20 employees $(66,66 \%)$ included in Normal category, and 10 employees (33,33\%) included in Light Work Fatigue. The result of bivariate analysis one way anova test $p>0,05$. The conclusion of this research is there is no correlation between work climate and fatigue towards employees of production. There is no difference of work climate in lathe, automotive, and construction. The suggested to the company to climate control work should need to have replacement roof of asbestos with a roof tile, to labor should not be at rest in the hot room to minimize contact with heat and time to the next suggested resear chers can examine the levels of dust and waste B3.
\end{abstract}

Keywords : Work Climate, Fatigue

\section{PENDAHULUAN}

Undang-Undang No.1 Th. 1970 tentang keselamatan kerja dimana undang-undang tersebut mengatur keselamatan kerja dalam segala tempat kerja baik di darat, air maupun udara, yang berada di dalam wilayah kekuasaan hukum Republik Indonesia. Syarat keselamatan kerja yang diatur dalam undang-undang tersebut antara lain ditetapkan

1) Email : riskatiyas94@yahoo.com

2) Email : pakzaeni@gmail.com

3) Email : budut17@yahoo.co.id kerja,alat kerja, cara dan proses kerja serta lingkungan kerja

Lingkungan kerja merupakan segala sesuatu yang berada di sekitar tenaga kerja yang dapat mempengaruhi dirinya dalam melaksanakan tugas dan pekerjaaan yang dibebankan. Dalam lingkungan kerja panas, tenaga kerja mendapatkan beban tambahan berupa tekanan panas (Zaenal.A dan Suharyo.W, 2009, h.521). Hal tersebut dapat 
memperburuk kondisi kesehatan dan stamina selama kerja. Lingkungan kerja panas merangsang tubuh untuk berkeringat sebagai proses alamiah guna menurunkan suhu tubuh hingga pada temperatur normal tubuh manusia yaitu $37^{\circ} \mathrm{C}$ (J.F. Gabriel, 1988, h.120). Salah satu tempat kerja yang dapat berpotensi menimbulkan panas adalah bengkel.

PT. Harapan Jaya Globalindo (HJG) merupakan perusahan perbengkelan yang bergerak dalam bidang jasa perbengkelan, penjualan spareparts mobil dan jasa produksi konstruksi, baik untuk wilayah banyumas maupun luar kota. Berdasarkan proses pekerjaan selain timbulnya Penyakit Akibat Kerja (PAK) yang disebabkan oleh human error lingkungan dapat berpotensi menimbulkan PAK berupa keluhan langsung maupun jangka panjang.Pekerja yang bekerja di lingkungan dengan suhu diatas zona aman seperti halnya di tempat produksi harus menanggung panas yang berasal dari hasil aktivitas tubuh juga menerima beban tambahan berupa panas dari lingkungan kerjanya. Terpapar oleh suhu yang tinggi selama bekerja dalam ruangan dengan lingkungan kerja panas atau bekerja di ruang terbuka dengan cuaca yang panas merupakan keadaan yang berpotensi menimbulkan bahaya Tujuan penelitian adalah untuk mengetahui hubungan iklim kerja dengan kelelahan pada tenaga kerja bagian produksi di PT. Hatapan Jaya Globalindo Tahun 2016.

\section{BAHAN DAN METODE}

Jenis penelitian adalah penelitian observasional menggunakan desain cross sectional. Populasi adalah seluruh tenaga kerja pada bagian produksi. Teknik pengambilan sampel menggunakan perhitungan rumus $\mathrm{Z}$ yaitu 48 tenaga kerja pada bagian produksi. Pengukuran kelelahan menggunakan alat reaction timer, dan pengukuran iklim kerja menggunakan ISBB yang terdiri dari suhu basah dan suhu bola. Hasil pengukuran dianalisis menggunakan soft ware analisis data yang terdiri dari analisis univariate untuk menggambarkan tiap variabel dan analisis bivariate menggunakan uji regresi sederhana.

\section{HASIL DAN PEMBAHASAN}

\section{Univariate}

\section{Kelelahan}

Hasil pengukuran kelelahan pada tenaga kerja sebanyak 30 responden dapat dijelaskan pada tabel 3.1 .

Tabel 3.1 Distribusi frekuensi kelelahan kerja di PT. Harapan Jaya Globalindo tahun 2016.

\begin{tabular}{cccc}
\hline $\begin{array}{c}\text { Ket. Waktu } \\
\text { Reaksi }\end{array}$ & Kategori & $\Sigma$ & $\%$ \\
\hline $\begin{array}{c}\text { 150 hingga } 240 \\
\text { milidetik }\end{array}$ & Normal & 20 & 66,66 \\
$>240$ hingga & KKR & 10 & 33,33 \\
$<410$ milidetik & KKS & 0 & 0 \\
410 hingga & & & \\
$<580$ milidetik & KKB & 0 & 0 \\
\hline 580 milidetik & & &
\end{tabular}

Keterangan : Normal

KKR : Kelelahan Kerja Ringan

KKS : Kelelahan Kerja Sedang

KKB : Kelelahan Kerja Berat

Hasil pengukuran kelelahan kerja pada bagian produksi di PT Harapan Jaya Globalindo dengan menggunakan reaction timer seperti dijelaskan pada tabel 4.3 diketahui 10 orang (33,33\%) termasuk dalam kategori Kelelahan Kerja Ringan (KKR) dan 20 orang $(66,66 \%)$ termasuk dalam kategori Normal.

\section{Iklim Kerja}

Pengukuran iklim kerja pada bagian produksi pada saat tenaga kerja meakukan pekerjaannya dapat dijelaskan pada tabel 3.2.

Tabel 3.2 Distribusi frekuensi Iklim Kerja di PT. Harapan Jaya Globalindo tahun 2016

\begin{tabular}{|c|c|c|c|}
\hline Lokasi & $\begin{array}{c}\text { Rata- } \\
\text { Rata }\left({ }^{\circ} \mathrm{C}\right)\end{array}$ & $\begin{array}{c}\text { Minimum } \\
\left({ }^{\circ} \mathrm{C}\right)\end{array}$ & $\begin{array}{l}\text { Maksimum } \\
\left({ }^{\circ} \mathrm{C}\right)\end{array}$ \\
\hline Produksi & 31,15 & 29,88 & 32,11 \\
\hline Menteri & Tenaga & Kerja & KEP- \\
\hline
\end{tabular}
51/MEN/1999 dengan waktu kerja terus menerus selama 8 jam per hari, pada kategori beban kerja ringan dengan $\mathrm{NAB} 30^{\circ} \mathrm{C}$. Pengukuran iklim kerja berdasakan rumus ISBB $=0,7 \mathrm{x}$ suhu basah $+0,3 \mathrm{x}$ suhu bola. Berdasarkan tabel 3.2 rata-rata iklim kerja pada ruang produksi yaitu $31,15{ }^{\circ} \mathrm{C}$ dengan nilai minimum $29,88^{\circ} \mathrm{C}$, dan maksimum $32,11^{\circ} \mathrm{C}$ yang berarti iklim kerja pada ruangan tersebut tidak memenuhi syarat.

Akibat yang membahayakan dari pemaparan berkepanjangan terhadap panas yang tinggi dapat menyebabkan kelainan. Adapun kelainan/gangguan yang dapat dilihat secara klinis akibat gangguan suhu yang tinggi yaitu kelelahan, dehidrasi, miliria rubria (Heat Rash), kelelahan panas (Heat exhaustion), kejang-kejang otot (Heat cramps), aliran udara ke otak kurang, dan heat stroke.

\section{Suhu Basah}

Pengukuran suhu basah dilakukan pada bagian produksi. Pengukuran dilakukan pada saat tenaga kerja melakukan pekerjaannya. Suhu basah (natural wet bulb temperature) yaitu suhu penguapan air, pada suhu yang sama menyebabkan terjadinya keseimbangan uap air diudara. Suhu basah alami 
diukur dengan termometer suhu basah (Suma'mur,2009).

Tabel 3.3 Distribusi frekuensi Suhu Basah di PT. Harapan Jaya Globalindo tahun 2016

\begin{tabular}{cccc}
\hline Lokasi & $\begin{array}{c}\text { Rata- } \\
\text { Rata }\left({ }^{\circ} \mathrm{C}\right)\end{array}$ & $\begin{array}{c}\text { Minimum } \\
\left({ }^{\circ} \mathrm{C}\right)\end{array}$ & $\begin{array}{c}\text { Maksimum } \\
\left({ }^{\circ} \mathrm{C}\right)\end{array}$ \\
\hline
\end{tabular}

$\begin{array}{llll}\text { Produksi } \quad 31,30 \quad 31,00 & 31,66\end{array}$

Hasil pengukuran suhu basah pada bagian produksi diketahui rata-rata suhu basah pada ruang produksi yaitu $31,30{ }^{\circ} \mathrm{C}$ dengan nilai minimum $31,00{ }^{\circ} \mathrm{C}$, dan maksimum $31,66{ }^{\circ} \mathrm{C}$. Hal ini seperti dijelaskan pada tabel 3.3

Suhu tersebut erat hubungannya dengan tingkat metabolism tubuh yang menghasilkan panas. Bekerja pada lingkungan kerja bersuhu tinggi dapat membahayakan bagi keselamatan dan kesehatan kerja sehingga untuk berkerja pada lingkungan dengan temperatur demikian perlu upaya penyesuaian waktu kerja dan perlindungan yang tepat kepada tenga kerja yang bersangkutan (Suma'mur,2009).

\section{Suhu Bola}

Pengukuran suhu bola dilakukan pada bagian produksi. Pengukuran dilakukan pada saat tenaga kerja melakukan pekerjaannya. Suhu Bola merupakan suhu yang diukur dengan menggunakan termometer suhu bola yang sensornya dimasukan kedalam bola tembaga yang dicat hitam, sebagai indikator tingkat radiasi (Suma'mur,2009)

Tabel 3.4 Distribusi frekuensi Suhu Bola di PT. Harapan Jaya Globalindo tahun 2016

\begin{tabular}{lccc}
\hline Lokasi & $\begin{array}{c}\text { Rata-Rata } \\
\left({ }^{\circ} \mathrm{C}\right)\end{array}$ & $\begin{array}{c}\text { Minimum } \\
\left({ }^{\circ} \mathrm{C}\right)\end{array}$ & $\begin{array}{c}\text { Maksimum } \\
\left({ }^{\circ} \mathrm{C}\right)\end{array}$ \\
\hline Produksi & 31,81 & 30,00 & 31,50
\end{tabular}

Hasil pengukuran suhu bola pada bagian produksi diketahui rata-rata suhu bola pada ruang produksi yaitu $31,81^{\circ} \mathrm{C}$ dengan nilai minimum 30,00 ${ }^{\circ} \mathrm{C}$, dan maksimum $31,50^{\circ} \mathrm{C}$. Hal ini dapat dijelaskan pada tabel 3.4 Suhu panas berakibat menurunkan prestasi kerja berfikir. Penurunan kemampuan berfikir terjadi apabila suhu melampaui $32{ }^{\circ} \mathrm{C}$. Suhu panas mengurangi kelincahan, memperpanjang waktu reaksi dan memperlambat waktu pengambilan keputusan, mengganggu kecermatan kerja otak, mengganggu koordinasi saraf perasa dan motoris, serta memudahkan terjadinya emosi (Suma'mur, 2009).

\section{Bivariate}

\section{Uji Regresi Sederhana}

Berdasarkan hasil uji analisis statistik pada analisis hubungan iklim kerja dengan kelelahan di PT Harapan Jaya Globalindo

Tabel 3.5 Hubungan Iklim Kerja dengan Kelelahan

\begin{tabular}{ccc}
\hline Indikator & Nilai & Kesimpulan \\
\hline $\mathrm{R}$ & 0,040 & Ha di tolak \\
$\mathrm{R}^{2}$ & 0,002 & \\
Anova & 0,918 & \\
\hline
\end{tabular}

Hasil uji statistik menunjukkan tidak ada hubungan antara panas radiasi dengan kelelahan kerja dengan $p$-value $=0,459$. Tabel 3.5 dapat diketahui Ha ditolak karena $\mathrm{R}$ hitung $<\mathrm{R}$ tabel.Nilai $\mathrm{R}$ digunakan untuk mengetahui kuat lemahnya hubungan karena $\mathrm{R}<0,040$ maka hubungan lemah. Nilai $\mathrm{R}$ square diketahui 0,002 yang artinya pengaruh iklim kerja terhadap kelelahan yaitu $0,2 \%$ sedangkan 99,8\% sisanya dipengaruhi oleh variabel lain. Uji anova menunjukkan taraf siginifikasinya $0,918>0,05$ maka persamaan garis tidak dapat dilanjutkan.

Iklim merupakan hasil perhitungan antara suhu basah dan suhu bola. Hasil statistik antara suhu basah dengan kelelahan kerja dengan $p$-value= 0,168. Tabel 3.3 dapat diketahui Ha ditolak karena R hitung $<\mathrm{R}$ tabel. Nilai $\mathrm{R}$ digunakan untuk mengetahui kuat lemahnya hubungan karena $\mathrm{R}<$ 0,182 maka hubungan lemah. Nilai $\mathrm{R}$ square diketahui 0,033 yang artinya pengaruh suhu basah terhadap kelelahan yaitu 3,3 \% sedangkan 97,3\% sisanya dipengaruhi oleh variabel lain. Uji anova menunjukkan taraf siginifikasinya $0,335>0,05$ maka persamaan garis tidak dapat dilanjutkan.

Hasil statistik antara suhu bola dengan kelelahan kerja dengan $p$-value $=0,278$. Tabel 3.4 dapat diketahui Ha ditolak karena $\mathrm{R}$ hitung $<\mathrm{R}$ tabel. Nilai $\mathrm{R}$ digunakan untuk mengetahui kuat lemahnya hubungan karena $\mathrm{R}<0,112$ maka hubungan lemah. Nilai R square diketahui 0,012 yang artinya pengaruh suhu basah terhadap kelelahan yaitu 1,2 \% sedangkan $98,8 \%$ sisanya dipengaruhi oleh variabel lain. Uji anova menunjukkan taraf siginifikasinya $0,557>0,05$ maka persamaan garis tidak dapat dilanjutkan.

Tidak ada hubungan antara iklim dan komponen iklim (suhu basah dan suhu bola) dengan kelelahan kerja pada penelitian ini disebabkan hasil pengukuran iklim kerja, suhu basah dan suhu bola tidak menunjukan hasil yang berbeda jauh karena berada dalam satu lokasi sehingga tidak bisa diidentifikasi oleh statistik dan hal ini dapat menggambarkan bahwa tenaga kerja yang terpapar panas sudah beraklimatisasi dengan iklim kerja yang ada di lokasi kerjanya. Aklimatisasi tenaga kerja dengan iklim pada penelitian ini merupakan suatu adaptasi tenaga kerja terhadap suatu lingkungan yang baru dan kondisi iklim kerja yang baru atau berbeda.

Aklimatisasi merupakan suatu proses yang pada akhirnya tercapai kesesuaian antara faktor manusia dan faktor iklim (cuaca). Proses penyesuaian 
demikian terutama penting pada saat awal seseorang berada pada iklim (cuaca) yang terhadapnya harus melakukan penyesuaian. Saat awal proses aklimatisasi yang memerlukan perhatian khusus pada saat minggu pertama seseorang berada di tempat dengan iklim (cuaca) baru. Pekerjaan dan tempat kerja pada umumnya beriklim kerja panas dimana biasanya tekanan panas tersebut melebihi keadaan sehari-hari pada umumnya. Pekerja baru yang mulai bekerja pada lingkungan kerja dengan lingkungan panas akan mengalami proses aklimatisasi terhadap intensitas paparan panas yang sebelumnya tidak pernah dialami Suma'mur, 2009).

Hal tersebut didukung oleh penelitian yang dilakukan oleh Fabiyanus Ristiyanto tahun 2009 yang menjelaskan tidak ada hubungan antara iklim kerja dengan kelelahan kerja dengan p value 0,111. Apabila antara iklim kerja berada dalam keadaan tidak seimbang (buruk) maka dapat mengganggu efektifitas kerja,dan sebaliknya apabila iklim kerja dalam keadaan baik maka akan meningkatkan kenyamanan dan mengurangi potensi bahaya yang ditimbulkan seperti penyakit akibat kerja (Fabiyanus Ristiyanto, 2009)

\section{Uji Anova One Way}

Uji anova one way digunakan untuk mengetahui perbedaan kelelahan pada tiap-tiap bagian. Dikatakan tidak ada perbedaan jika p value $>0,05$ dan dikatakan ada perbedaan jika p value $<0,05$.

Tabel 3.6 Perbedaan kelelahan di bagian konstruksi, otomotif, dan bubut

\begin{tabular}{lll}
\hline Nama Bagian & $\mathrm{p}$-value & Keterangan \\
\hline $\begin{array}{l}\text { Otomotif dengan } \\
\text { konstruksi }\end{array}$ & 0,452 & Tidak ada beda \\
$\begin{array}{l}\text { Otomotif dengan } \\
\text { Bubut }\end{array}$ & 0,751 & Tidak ada beda \\
$\begin{array}{l}\text { Konstruksi } \\
\text { dengan otomotif }\end{array}$ & 0,452 & Tidak ada beda \\
$\begin{array}{l}\text { Konstruksi } \\
\text { dengan bubut }\end{array}$ & 0,270 & Tidak ada beda \\
$\begin{array}{l}\text { Bubut dengan } \\
\text { otomotif }\end{array}$ & 0,751 & Tidak ada beda \\
$\begin{array}{l}\text { Bubut dengan } \\
\text { konstruksi }\end{array}$ & 0,270 & Tidak ada beda \\
\hline
\end{tabular}

Hasil uji statistik anova one way untuk mengetahui perbedaan kelelahan di bagian konstruksi, otomotif, dan bubut pada tabel 3.6 didapatkan hasil $\mathrm{p}$ value $>0,05$ sehingga dapat disimpulkan tidak ada perbedaan kelelahan pada tiap-tiap bagian. Hal tersebut dikarenakan hasil pengukuran kelelahan kerja pada tiap bagian hampir sama, sehingga tidak ada beda yang signifikan pada tiap-tiap bagian.

Perusahaan sebaiknya melakukan penggantian atap dari asbes, dengan atap sejenis keramik yang berbahan dasar tanah liat dan dapat memantulkan panas matahari dan tenaga kerja sebaiknya pada saat istirahat tidak berada pada ruangan yang panas untuk meminimalisir kontak dengan panas.

\section{SIMPULAN DAN SARAN}

\section{SIMPULAN}

Hasil pengukuran iklim kerja pada bagian produksi di dapatkan rata-rata $31,15{ }^{\circ} \mathrm{C}$, rata-rata pengukuran suhu basah $31,30{ }^{\circ} \mathrm{C}$, dan rata-rata pengukuran suhu bola $31,81{ }^{\circ} \mathrm{C}$. Hasil pengukuran kelelahan pada bagian produksi didapatkan rata-rata 229,71 milidetik dengan nilai minimum 167,74 milidetik dan maksimum 319,15 milidetik Tidak ada hubungan antara iklim kerja dengan kelelahan pada bagian produksi dengan $\mathrm{p}$-value 0,238 , R hitung 0,135 , $\mathrm{R}$ square 0,018 dan hasil anova 0,477 menggunakan regresi sederhana dan dilanjutkan untuk mengetahui perbedaan kelelahan pada tiap bagianmenggunakan uji anova one way dengan nilai p valu $>0,05$ sehingga tidak ada beda kelelahan pada tiap-tiap bagian.

\section{SARAN}

\section{Bagi Perusahaan}

Peneliti menyarankan bagi perusahaan agar melakukan penggantian atap dari asbes menjadi atap genteng

\section{Bagi Tenaga Kerja}

Peneliti menyarankan bagi tenaga kerja sebaiknya tidak berada pada ruangan yang panas untuk meminimalisir kontak dengan panas

\section{Bagi Peneliti Selanjutnya}

Peneliti menyarankan untuk peneliti selanjutnya dapat meneliti kadar debu dan limbah B3di PT Harapan Jaya Globalindo

\section{DAFTAR PUSTAKA}

A.M. Sugeng Budiono, 2003, Bunga Rampai Hiperkes dan KK, Semarang : UniversitasDiponegoro.

Ambar Silastuti, 2006, Hubungan Antara Kelelahan dengan Produktivitas TenagaKerja di Bagian Penjahitan PT. Bengawan Solo Garment Indonesia,Skripsi, Semarang : Universitas Negeri Semarang.

Aris Santjaka, 2011, Statistik Untuk Penelitian Kesehatan, Yogyakarta : Nuha Medika

Arthur Gyton dan John E. Hall, 1999, Buku Ajar Fisiologi Kedokteran (alih Bahasa: Irawati Setiawan, Jakarta: ECG. 
Carolin Wijaya, 1995, Deteksi Dini Penyakit Akibat Kerja (alih bahasa: Joko Suyono), Jakarta: ECG-WHO.

Deny Ardyanto, 2005, Potret Iklim Kerja, Jurnal kesehatan lingkungan, Volume 1

Djamaluddin Ramlan, 2006, Dasar-Dasar Kesehatan Kerja, Purwokerto: Unsoed

Djamaludin Ramlan dan Maisje Marlyn Kuhu, 2013, Dasar Statistik Penelitian, Purwokerto : Universitas Jendral Soedirman Purwokerto

Eko Nurmianto, 2003, Ergonomi Konsep Dasar dan Aplikasinya, Surabaya : GunaWijaya.

Endah Tri Wulandari, 2004, Hubungan Antara Kebisingan Dan Tekanan Panas Dengan Kelelahan Pada Operator Di Bagian Injeksi PT Arisa Mandiri Pratama,Semarang : UNDIP

Herry Koesyanto dan Eram Tunggul Pawenang, 2005, Panduan PraktikumLaboratorium Kesehatan dan Kesehatan Kerja, Semarang : UPT UNNES Press

Humantech. 1995. Applied Ergonomics Training Manual 2nd Edition. Australia: Barkeley Vale ( Terjemahan)

I Dewa Nyoman Supariasa, 1999, Penilaian Status Gizi, Jakarta: EGC

I Ketut Gede Juli Suarbawa, 2004, Pemberian Kudapan dan Istirahat Pendek Menurunkan Kehilangan Berat Badan, Beban Kerja Dan Keluhan Subjektif Serta Meningkatkan Produktifitas Perajin Gamelan Di Desa TihinganKabupaten Klungkung, Jurnal Ergonomi Indonesia, Vol 5, No 1 Juni 2004

J.F. Gabriel, 1988, Fisika Kedokteran, Jakarta : EGC.

Jurnal Teknik Industri, Vol. 14, No. 2, Desember 2012, 129-136 ISSN 1411-2485

Lientje Setyawati K Maurits, 2011, Selintas Tentang Kelelahan Kerja, Yogyakarta : Amara Books

Margatan, 1996, Hidup Sehat Bagi Usia Lanjut, Jakarta: Penerbit Buku Kedokteran EGC.
Nurli Faiz, Faktor-faktor yang berhubungan dengan kelelahan kerja pada pekerja bagian operator SPBU di kecamatan ciputat 2012.Program Studi Kesehatan masyarakat UIN Jakarta

Ramadhani, S. 2003. Bunga Rampai Hiperkes dan KK. Semarang: Badan Penerbit UNDIP

Ristiyanto Fabianus, 2009. Hubungan paparan iklim kerja panas dengan kelelahan kerja setelah bekerja di unit boiler PT. Tiga Pilar Sejahtera Food, Tbk Sepat, Masaran, Sragen, Jawa Tengah. Program Diploma III Hiperkes dan K3 Uns Surakarta

Sanders, M. S. dan McCormick., E. J. 1987. Human Factors in Engineering and Design. New York: McGraw-hill (Terjemahan)

Soedirman dan Suma'mur PK, 2014,Kesehatan Kerja Dalam Perspektif Hiperkes Dan Keselamatan Kerja, Jakata : Erlangga

Soeripto M, 2008, Higiene Industri, Jakarta : Fakultas Kedokteran Universitas Indonesia

Sum'mur P.K, 1996, Higiene Perusahaan dan Keselamatan Kerja, Jakarta : GunungAgung.

2009, Higiene Perusahaan Dan Keselamatan Kerja (HIPERKES), Sagung Seto

Tarwaka, Solikhul Bakri HA, Lilik Sudiajeng, 2004, Ergonomi untukKeselamatan Kerja dan Produktivitas, Surakarta : UNIBA Press

2014, Ergonomi Industri, Surakarta: Harapan Press

Wowo Sunaryo Kuswana, 2014, Ergonomi dan K3, Bandung: Pt. Remaja Rosdakarya

Zaenal.A dan Suharyo. W, 2009, Studi Literatur Tentang Lingkungan Kerja Fisik Perkantoran, Makalah disajikan dalam Seminar Nasional V SDM Teknologi Nuklir, STTN Batan Yogyakarta, 5 November 2009. 